\title{
DEVELOPMENT OF RESEARCH IN NORTHERN AUSTRALIA
}

\begin{abstract}
$\mathrm{A}^{\mathrm{N}}$ $\mathrm{N}$ important advance in the development of northern Australia occurred recently when the Minister-in-Charge of the Commonwealth Scientific and Industrial Research Organization, Senator Gorton, opened a new research laboratory at the C.S.I.R.O.'s Coastal Plains Research Station. The Station is situated forty miles east of Darwin, close to Humpty Doo.

The aim of the research workers in this laboratory, in collaboration with Northern Territory authorities, is to develop agricultural procedures for the development of the coastal plains in the Northern Territory. The crop plant receiving major attention is tropical rice. The breeding of special rice varieties, the determination of planting, harvesting and fertilizer techniques to meet the particular conditions of the area, form an important part of this work. The possibility of forms of agricultural development other than rice are also to be examined.

Work commenced at the Station in 1959 when the Commonwealth Government, through the Northern Territory Administration, provided $£ 124,000$ for its capital development and $£ 50,000$ per annum for running costs. Since that time it has been possible to provide accommodation and special facilities to enable research workers to carry out their programme under tropical conditions. These facilities have attracted $a$ staff of fifteen officers to the Station.

The agricultural development which has so far taken place in Australia has mainly evolved from European agricultural practices although Australian scientists have solved many of the problems peculiar
\end{abstract}

to the Australian environment, particularly in tropical Queensland. The essential European temperate agricultural background has resulted in greater development of the southern areas of Australia, and only within the past decade or two has Australia been able to divert its scientific effort to the less-developed areas of the northern environment.

More than half a million square miles of northern Australia have now been surveyed and mapped by C.S.I.R.O. scientists. Large areas have also been examined for possible mineral development by the Bureau of Mineral Resources.

The development which is now occurring at the Coastal Plains Research Station is a further step forward in the essential advances of this vast area. The station is one of a number of C.S.I.R.O. units working on agricultural problems of the north. Others are located at the Ord River in the Kimberley region of Western Australia, at Katherine and Alice Springs in the Northern Territory, and at Mareeba, Ingham, Rockhampton, Brisbane and Cunnamulla in Queensland.

The proposed establishment of a new pasture research laboratory at Townsville also indicates the strong desire of the Government to provide a sound scientific basis for the development of these areas.

All these, in conjunction with the activities of the Northern Territory Administration Technical Services, will contribute to the eventual development of a vast region, the potential of which has scarcely been touched.

\section{THE ARTHUR D. LITTLE RESEARCH INSTITUTE}

T HE annual report of the Arthur D. Little Research Institute for 1961 * also briefly reviews the first five years achievements of the Institute, and, besides a list of senior staff, includes a list of the Acorn Lectures delivered since January 1958. Lists of publications are included under the severa] sections. The Biochemistry and Biophysics Section is now well established, and during the year centred on isolated wheat gluten. Starch-gel electrophoresis has shown that there are at least 26 protein components and paper chromatography that the phospholipids of flour are present in the same complexity in isolated gluten. Equipment has been designed to study the fundamental properties of gluten as an elastomeric gel.

The Organic Chemistry Section has prepared a range of stable true sodium sucrates up to the hepta derivative and studied their reactions with more than 50 chloro compounds, particularly the reactivity of penta-sodium sucrate under mild conditions in the presence of dimethoxyethane. Other work has been concerned with the polymerization of glucose and its derivatives, the preparation of carbohydrate polyamides with viscosities comparable with that of nylon by interfacial polycondensation, polyglucoses and the chemical modification of wood, for example, its

* Arthur D. Little Research Institute. Annual Report for 1961. Pp. 46. (5th Anniversary Report.) (Inveresk, Midlothian: Arthur D. Pp. 46. (5th Anniversary phosphorylation, the dimensional stability of wood, the preparation of chlorinated phenyl derivatives of cellulose and the emission of corrosive volatiles from wood, while early in 1960 the study of the chemistry of ethylene sulphide was begun.

In physical chemistry, the polymer group has been. concerned with the mechanism and kinetics of formation of 'isotactic' polymers and with certain of their bulk properties with the view of a better understanding of the effect of structural and environmental parameters. The kinetics of the reaction between molten aluminium and water vapour at about $1,000^{\circ} \mathrm{C}$. have also been studied, while the Metallurgy Section has attempted to establish relations between the effectiveness as corrosion inhibitor of an additive in aqueous solution and its molecular structure. Although $\mathbf{4 7 0}$ inhibitors were tested, no clearly defined relation was established between threshold concentration and molecular structure. A study was also made of the influence of additives on the relation between applied current and metal potential for both cathodic oxygen reduc. tion and anodic metal dissolution. Investigations have commenced on the hydrogen embrittlement of very strong steels with the view of devising a procedure for acid pickling which avoids subsequent hydrogen embrittlement. 